Original Research Paper

\title{
Effects of Artemisinin-Based Combination Therapies on Lipids and Hepatorenal Circulating Indices in Guinea Pigs
}

\author{
${ }^{1}$ Abaram Chesa Mankwe, ${ }^{2}$ Jonah Sydney Aprioku and ${ }^{3}$ Atuboyedia Wolfe Obianime \\ ${ }^{I}$ Cardiology Division, Department of Internal Medicine, Federal Medical Centre, Yenagoa, Bayelsa State, Nigeria \\ ${ }^{2}$ Department of Experimental Pharmacology and Toxicology, \\ Faculty of Pharmaceutical Sciences, University of Port Harcourt, Port Harcourt, Nigeria \\ ${ }^{3}$ Department of Pharmacology, Faculty of Basic Medical Sciences, \\ University of Port Harcourt, Port Harcourt, Port Harcourt, Nigeria
}

Article history

Received: 24-01-2017

Revised: 09-03-2017

Accepted: 16-03-2017

Corresponding Author:

Jonah Sydney Aprioku

Department of Experimental

Pharmacology and Toxicology,

Faculty of Pharmaceutical

Sciences, University of Port

Harcourt, Port Harcourt,

Nigeria

Ph: $+234(0) 8035082379$

Email: sydaprio@yahoo.com

\begin{abstract}
Artemisinin-based Combination Therapies (ACTs) are employed as first-line agents in malaria chemotherapy. In many malaria endemic areas, ACTs are frequently abused partly due to resistance, poor drug control and inadequate health facilities. This study investigated the effects of prolong administration of Artesunate-Sulfadoxine-Pyrimethamine (ATSSP), Artesunate-Amodiaquine (ATS-Amod) and Artemether-Lumefantrine (ATM-Lum) on plasma levels of biochemical parameters (AST, ALT, ALP, urea and creatinine) and lipids in guinea pigs. Adult guinea pigs were administered standard (NTD) or Double Therapeutic Dose (DTD) equivalents of ATS-SP, ATS-Amod or ATM-Lum for 14 days. Some other animals received similar drug treatments but were allowed to recover for 14 days. Control group was given vehicle. ATS-Amod caused significant $(\mathrm{p}<0.05)$ elevations in AST, ALT, urea and creatinine levels without altering ALP compared to control. The elevations were all reversed except the DTD-induced creatinine elevation. ATS-SP reversibly elevated $(\mathrm{p}<0.05)$ AST and creatinine levels. ATM-Lum caused no effect on urea, creatinine and ALT, but increased AST and ALP levels. Lipids were unaffected, except triglyceride level that was reversibly elevated $(p<0.05)$ by ATS-SP (DTD). The results demonstrate that standard doses of the ACTs may have no harmful effects, but prolong overdose treatment with artesunate-amodiaquine or artesunate-SP may elevate creatinine and triglyceride levels, respectively.
\end{abstract}

Keywords: ACTs, Artemisinin, Creatinine, Lipids, Prolong Treatment, Triglyceride

\section{Introduction}

Malaria is a public health disease which is endemic in the sub Saharan region and it has remained a leading cause of mortality and morbidity in the developing world (Breman et al., 2004). There are many drugs available for malaria treatment, but poor therapeutic outcome due to treatment failures is common and this had impacted negatively on man's health and economy (Sachs and Malaney, 2002). Treatment failures have been linked majorly to the development of resistance of the malaria parasite (plasmodium) to standard antimalarial agents (Rønn et al., 1996; Ogutu et al., 2000; Djimdé et al., 2001). This has necessitated the search for new and more effective drugs resulting in the development of artemisinin and its derivatives (artesunate, artelinic acid, artemether, arteether and dihydroartemisinin).

Artemisinins are highly effective against the plasmodium parasite (Harinasuta and Qinghaosu, 1994; Hien, 1994). They are believed to produce their antiplasmodial activities via generation of free radicals with subsequent alkylation of the parasite's membrane (Heppner and Ballou, 1998). Currently, Artemisininbased Combination Therapies (ACTs) are recommended as the first line agents for the treatment of uncomplicated malaria (Nosten and White, 2007). Expectedly, these agents are used widely and frequently in endemic areas of the disease, including Nigeria. But sadly, there is a 
serious concern of their misuse as ACTs and other antimalarial drugs are readily purchased over-thecounter in most parts of these regions and selfmedication is a common practice (Akanbi et al., 2005). Also, wrong diagnosis of other fever related conditions for malaria (in both clinical and nonclinical settings) is not uncommon and patients are therefore treated repeatedly with antimalarial agents in these areas. The consequence of this is overdose and prolong usage of ACTs which raises the concern of drug toxicity (Jaeger et al., 1987).

Previous works have reported that therapeutic dose levels of artemisinins exhibit potential neuro- and reproductive toxicities (Raji et al., 2005; Nwanjo et al., 2007; Aprioku and Obianime, 2011). Artemisinin derivatives (artesunate and artemether) and ACTs (artesunate-sulfadoxine-pyrimethamine, artesunateamodiaquine) have equally been reported to alter plasma levels of biochemical parameters of different organ functions, including alkaline phosphatase, acid phosphatase, urea, creatinine, uric acid and total cholesterol in animals (Adaramoye et al., 2008; Obianime and Aprioku, 2011; Ugian et al., 2013; Etim et al., 2016). There is therofore a compelling need to assess the impact of overdose and prolong use of artemisinins as they are often misued in Africa and other sub Saharan countries. Apparently, this is yet to be studied. İn this work, the effects of fourteen days daily administrations of standard or double therapeutic dose equivalents of three frequently used ACTs (artesunate-amodiaquine, artesunate-sulfadoxinepyrimethamine and artemether-lumefantrine) on plasma levels of renal and hepatic biochemical indices were investigated in the guinea pig. We equally evaluated their effects on lipid levels as well as the reversibility of these effects.

\section{Materials and Methods}

\section{Drugs}

Artesunate-amodiaquine, Winthrop ${ }^{\circledR}$ (Sanofi-aventis, France), artesunate-SP, Farenax ${ }^{\circledR}$ (Swiss Pharma Nigeria Ltd., Nigeria) and artemether-lumefantrine, Fynale ${ }^{\circledR}($ NAXPAR Laboratory PVT Ltd., India) tablets were obtained from the Pharmacy Unit, University of Port Harcourt Teaching Hospital, Port Harcourt, Nigeria.

\section{Animals}

Sixty five out bred strains of adult male guinea pigs, weighing $450 \pm 5 \mathrm{~g}$ were obtained from the Animal House of the University of Port Harcourt, Nigeria and housed within the experimental animal handling facility of the Department of Pharmacology University of Port Harcourt. They were maintained with standard rodent chow and given free access to tap water under natural conditions, with temperature of $26 \pm 4^{\circ} \mathrm{C}$. The animals were handled in accordance with international guidelines for care and use of laboratory animals in biomedical research. Experimental methods were done in accordance with the approved guideline of the Research Ethics Committee of the University of Port Harcourt, Nigeria.

\section{Experimental Design}

The guinea pigs were randomly divided into thirteen groups (1-13) containing 5 animals per group. Group 1-6 animals were administered artesunate-amodiaquine (4/10 or $8 / 20 \mathrm{mg} \mathrm{kg}^{-1} \mathrm{day}^{-1}$ ), artesunate-SP (4 plus $1.25 / 25$ or 8 plus $2.5 / 50 \mathrm{mg} \mathrm{kg}^{-1} \mathrm{day}^{-1}$ ) and artemether-lumefantrine (4.4/27.2 or $8.8 / 54.42 \mathrm{mg} \mathrm{kg}^{-1}$ day $^{-1}$ ), respectively, for 14 days. Similar drug treatments were given to groups 712 (recovery groups), while group 13 (control) rats received distilled water. The drugs were dissolved in distilled water and given by oral gavage. The lower doses of the drugs used were equivalent to their standard doses for the treatment of uncomplicated malaria in humans (Adjuik et al., 2002; Basco et al., 2002; Barnes et al., 2005, respectively). Twenty-four hours following the last treatment, all pigs were deeply anesthetized with diethyl ether and killed by cervical dislocation, except recovery group animals. Recovery groups (7-12) were allowed to recover for 14 days after treatment before they were sacrificed. Blood was withdrawn with sterile needles and syringes into lithium heparinized bottles via cardiac puncture. Plasma was separated by centrifugation and analyzed to measure the concentrations of Alanine Transaminase (ALT), Aspartate Transaminase (AST), Alkaline Phosphatase (ALP), urea, creatinine and lipids (total cholesterol, triglycerides, LDL and HDL) using a Clinical Chemistry Mindray Auto-analyzer (Model: BS-800m; Guangzou Shihal Medical Equipment Co. Ltd., China).

\section{Statistical Analysis}

Data are presented as mean \pm Standard Error of Mean (SEM). Differences between groups were determined by one-way Analysis of Variance (ANOVA) followed by Duncan's multiple comparison test for intergroup comparisons. Data were analyzed using Statistical Package for Social Sciences (SPSS) software for windows, $p<0.05$ was considered significant.

\section{Results}

\section{Effects of ACTs on Hepatic Enzymes}

Normal and double therapeutic dose treatments of artesunate-amodiaquine had no effect on Alkaline Phosphatase (ALP) enzyme plasma level, but caused significant $(\mathrm{p}<0.05)$ elevations in Aspartate Transaminase (AST) and alanine transaminase, ALT levels (Table 1). Artesunate-SP caused significant $(\mathrm{p}<0.05)$ elevation of AST, but produced no change in ALT and ALP levels, compared to control (Table 1). Elevation of AST was 
observed in normal and double therapeutic dose treated groups (Table 1). Furthermore, artemether-lumefantrine caused significant $(\mathrm{p}<0.05)$ elevations of AST (normal and double therapeutic dose) and ALP (double therapeutic dose), but had no effect on ALT, compared to control (Table 1). In all three ACT treated recovery groups, the enzyme levels were not significantly $(p>0.05)$ different compared to control (Table 1).

Table 1. Effects of 14 days treatments with Artesunate-Amodiaquine (ATS-Amod), Artesunate-Sulfadoxine-Pyrimethamine (ATSSP) and Artemether-Lumefantrine (ATM-Lum) on plasma Aspartate Transaminase (AST), Alanine Transaminase (ALT) and Alkaline Phosphatase (ALP) levels in guinea pigs

\begin{tabular}{|c|c|c|c|c|c|c|}
\hline \multirow[b]{2}{*}{ Dose } & \multicolumn{2}{|l|}{$\operatorname{AST}\left(\mathrm{IUL}^{-1}\right)$} & \multicolumn{2}{|l|}{$\operatorname{ALT}\left(\mathrm{IUL}^{-1}\right)$} & \multicolumn{2}{|l|}{$\operatorname{ALP}\left(\mathrm{IUL}^{-1}\right)$} \\
\hline & Treated group & Recovery group & Treated group & Recovery group & Treated group & Recovery group \\
\hline Control & $30.00 \pm 2.27$ & & $28.00 \pm 1.68$ & & $18.00 \pm 2.35$ & \\
\hline NTD (ATS-Amod) & $66.00 \pm 9.07 *$ & $60.75 \pm 36.80$ & $37.33 \pm 1.86 *$ & $20.00 \pm 0.71$ & $16.00 \pm 2.21$ & $26.67 \pm 2.96$ \\
\hline DTD (ATS-Amod) & $97.67 \pm 10.84 * *$ & $79.00 \pm 35.00$ & $37.33 \pm 2.67 *$ & $18.75 \pm 2.06$ & $18.00 \pm 3.70$ & $26.33 \pm 2.91$ \\
\hline NTD (ATS-SP) & $121.75 \pm 16.45 * *$ & $59.25 \pm 18.35$ & $32.25 \pm 14.91$ & $28.75 \pm 2.66$ & $16.00 \pm 1.87$ & $16.50 \pm 1.04$ \\
\hline DTD (ATS-SP) & $170.50 \pm 12.31 * *$ & $60.25 \pm 15.05$ & $41.00 \pm 1.68$ & $29.00 \pm 2.97$ & $15.75 \pm 1.18$ & $29.25 \pm 7.58$ \\
\hline NTD (ATM-Lum) & $196.75 \pm 13.18 * *$ & $54.00 \pm 10.21$ & $30.50 \pm 1.26$ & $24.50 \pm 2.50$ & $24.00 \pm 5.07$ & $12.50 \pm 1.32$ \\
\hline DTD (ATM-Lum) & $252.50 \pm 12.18 * *$ & $61.00 \pm 14.58$ & $32.50 \pm 1.71$ & $27.50 \pm 1.66$ & $35.50 \pm 3.52 *$ & $11.75 \pm 0.48 *$ \\
\hline
\end{tabular}

Data expressed as mean \pm SEM, $\mathrm{n}=5$

* Significantly different from control at $\mathrm{p}<0.05$

$* *$ Significantly different from control at $\mathrm{p}<0.01$

NTD: Normal Therapeutic Dose

DTD: Double Therapeutic Dose

Table 2. Effects of 14 days treatments with Artesunate-Amodiaquine (ATS-Amod), Artesunate-Sulfadoxine-Pyrimethamine (ATSSP) and Artemether-Lumefantrine (ATM-Lum) on plasma urea and creatinine levels in guinea pigs

\begin{tabular}{|c|c|c|c|c|}
\hline \multirow[b]{2}{*}{ Dose } & \multicolumn{2}{|l|}{ Urea $\left(\mathrm{mmolL}^{-1}\right)$} & \multicolumn{2}{|c|}{ Creatinine $\left(\mu \mathrm{molL}^{-1}\right)$} \\
\hline & Treated group & Recovery group & Treated group & Recovery group \\
\hline Control & $4.40 \pm 0.53$ & & $37.00 \pm 3.56$ & \\
\hline NTD (ATS-Amod) & $12.85 \pm 2.60 * *$ & $5.80 \pm 0.76$ & $45.00 \pm 1.87 *$ & $44.33 \pm 5.21$ \\
\hline DTD (ATS-Amod) & $12.30 \pm 2.10 * *$ & $6.30 \pm 1.08$ & $50.50 \pm 1.94 * *$ & $55.00 \pm 2.08 *$ \\
\hline NTD (ATS-SP) & $9.58 \pm 0.95$ & $5.03 \pm 0.45$ & $46.50 \pm 2.33 *$ & $45.00 \pm 1.00$ \\
\hline DTD (ATS-SP) & $10.75 \pm 2.71$ & $5.43 \pm 0.34$ & $48.00 \pm 1.87 *$ & $46.00 \pm 4.44$ \\
\hline NTD (ATM-Lum) & $6.03 \pm 1.82$ & $4.58 \pm 0.27$ & $40.50 \pm 1.76$ & $44.00 \pm 0.58$ \\
\hline DTD (ATM-Lum) & $5.03 \pm 0.42$ & $4.23 \pm 0.17$ & $47.25 \pm 3.01$ & $43.00 \pm 1.23$ \\
\hline
\end{tabular}

Data expressed as mean \pm SEM, $\mathrm{n}=5$

$*$ Significantly different from control at $\mathrm{p}<0.05$

$* *$ Significantly different from control at $\mathrm{p}<0.01$

NTD: Normal Therapeutic Dose

DTD: Double Therapeutic Dose

Table 3. Effects of 14 days treatments with Artesunate-Amodiaquine (ATS-Amod), Artesunate-Sulfadoxine-Pyrimethamine (ATSSP) and Artemether-Lumefantrine (ATM-Lum) on plasma levels of lipids in guinea pigs

\begin{tabular}{|c|c|c|c|c|c|c|c|c|}
\hline \multirow[b]{2}{*}{ Dose } & \multicolumn{2}{|c|}{$\begin{array}{l}\text { Total cholesterol } \\
\left(\mathrm{mmol} \mathrm{L}^{-1}\right)\end{array}$} & \multicolumn{2}{|l|}{$\begin{array}{l}\text { Triglyceride } \\
\left(\mathrm{mmol} \mathrm{L}^{-1}\right)\end{array}$} & \multicolumn{2}{|c|}{$\begin{array}{l}\text { High density } \\
\text { lipoprotein }\left(\mathrm{mmol} \mathrm{L}^{-1}\right)\end{array}$} & \multicolumn{2}{|c|}{$\begin{array}{l}\text { Low density } \\
\text { lipoprotein }\left(\mathrm{mmol} \mathrm{L}^{-1}\right)\end{array}$} \\
\hline & $\begin{array}{l}\text { Treated } \\
\text { group }\end{array}$ & $\begin{array}{l}\text { Recovery } \\
\text { group }\end{array}$ & $\begin{array}{l}\text { Treated } \\
\text { group }\end{array}$ & $\begin{array}{l}\text { Recovery } \\
\text { group }\end{array}$ & $\begin{array}{l}\text { Treated } \\
\text { group }\end{array}$ & $\begin{array}{l}\text { Recovery } \\
\text { group }\end{array}$ & $\begin{array}{l}\text { Treated } \\
\text { group }\end{array}$ & $\begin{array}{l}\text { Recovery } \\
\text { group }\end{array}$ \\
\hline Control & $0.54 \pm 0.12$ & & $0.24 \pm 0.07$ & & $0.25 \pm 0.09$ & & $0.18 \pm 0.07$ & \\
\hline NTD (ATS-Amod) & $1.39 \pm 0.12$ & $0.44 \pm 0.09$ & $0.47 \pm 0.07$ & $0.14 \pm 0.01$ & $0.37 \pm 0.04$ & $0.32 \pm 0.09$ & $0.81 \pm 0.16$ & $0.06 \pm 0.02$ \\
\hline DTD (ATS-Amod) & $1.00 \pm 0.39$ & $0.51 \pm 0.06$ & $0.37 \pm 0.04$ & $0.26 \pm 0.12$ & $0.16 \pm 0.08$ & $0.26 \pm 0.10$ & $0.67 \pm 0.33$ & $0.13 \pm 0.06$ \\
\hline NTD (ATS-SP) & $0.85 \pm 0.28$ & $0.41 \pm 0.06$ & $0.35 \pm 0.10$ & $0.26 \pm 0.07$ & $0.21 \pm 0.12$ & $0.9 \pm 0.04$ & $0.49 \pm 0.15$ & $0.21 \pm 0.05$ \\
\hline DTD (ATS-SP) & $1.05 \pm 0.17$ & $0.39 \pm 0.04$ & $0.54 \pm 0.06^{*}$ & $0.13 \pm 0.02$ & $0.37 \pm 0.15$ & $0.22 \pm 0.08$ & $0.43 \pm 0.06$ & $0.11 \pm 0.07$ \\
\hline NTD (ATM-Lum) & $0.88 \pm 0.22$ & $0.27 \pm 0.05$ & $0.36 \pm 0.03$ & $0.17 \pm 0.04$ & $0.19 \pm 0.10$ & $0.11 \pm 0.06$ & $0.54 \pm 0.12$ & $0.8 \pm 0.02$ \\
\hline DTD (ATM-Lum) & $0.66 \pm 0.22$ & $0.30 \pm 0.06$ & $0.27 \pm 0.07$ & $0.15 \pm 0.01$ & $0.14 \pm 0.12$ & $0.9 \pm 0.04$ & $0.40 \pm 0.07$ & $0.15 \pm 0.07$ \\
\hline
\end{tabular}

Data expressed as mean \pm SEM, $\mathrm{n}=5$

* Significantly different from control at $\mathrm{p}<0.05$

$* *$ Significantly different from control at $\mathrm{p}<0.01$

NTD: Normal Therapeutic Dose; DTD: Double Therapeutic Dose 


\section{Effects of ACTs on Urea and Creatinine}

Artesunate-amodiaquine increased plasma levels of urea and creatinine significantly $(p<0.05)$ and dosedependently (Table 2). In artesunate-amodiaquine treated recovery groups, urea levels were not altered, but creatinine level in double therapeutic dose treated group was increased compared to control (Table 2). In addition, artesunate-SP treatment (normal and double therapeutic dose) caused increase in creatinine level, but produced no change in urea level (Table 2). The plasma levels of urea and creatinine in artesunate-SP treated recovery animals were not significantly differently compared to control (Table 2). Furthermore, artemetherlumefantrine treatment did not cause change in the levels of urea and creatinine and none of the parameters was altered as well in the recovery animals when compared with the control (Table 2).

\section{Effects of ACTs on Lipids}

Normal and double therapeutic dose treatments of artesunate-amodiaquine and artemether-lumefantrine had no effect on plasma levels of total cholesterol, triglyceride, high density lipoprotein and low density lipoprotein, compared to control (Table 3). ArtesunateSP did not affect all the lipids except triglyceride which was elevated, $p<0.05$. Triglyceride elevation was observed only in pigs that received double therapeutic dose of the drug. Plasma levels of lipids obtained in all recovery groups were normal compared to control (Table 3).

\section{Discussion}

In this study, the effects of normal and double therapeutic dose treatments of artesunate-amodiaquine, artesunate-sulfadoxine-pyrimethamine (artesunate-SP) and artemether-lumefantrine on plasma levels of (1) hepatic enzymes-aspartate transaminase (AST), Alanine Transaminase (ALT) and Alkaline Phosphatase (ALP), (2) renal biochemical indices- urea and creatinine and (3) lipids-total cholesterol, triglycerides, High Lipids Lipoprotein (HDL) and Low Lipids Lipoprotein (LDL) were investigated in male guinea pigs. The regimens selected are among the most frequently prescribed Artemisinin-based Combination Therapies (ACTs) for malaria treatment, globally.

AST and ALT plasma levels were increased by normal and double therapeutic doses of artesunateamodiaquine, whereas it had no effect on ALP. Elevation of AST and ALT by artesunate-amodiaquine may have resulted from damage to hepatic cell and leakage of enzymes into circulation (Bhattacharyya et al., 2003; Nyblom et al., 2006). The implication of this is that prolong treatment with standard or overdose of artesunate-amodiaquine may affect liver function in the guinea pig, but this is unlikely to be of pathological concern as both AST and ALT elevations were reversed when drug administration was terminated. Additionally, normal and double therapeutic dose levels of artesunateSP reversibly increased AST level, but had no effect on ALT and ALP. Furthermore, artemether-lumefantrine reversibly increased AST and ALP levels, but did not affect ALT, however, only double therapeutic dose of the ACT increased ALP, while AST was elevated by both doses. In an earlier study, Ugian et al. (2013) have reported that intraperitoneal administration of artemether-lumefantrine elevates serum levels of AST, ALT and ALP in pregnant Wistar rats and may cause hepatic injury in pregnancy. The results of the present study suggest that artesunate-SP and artemetherlumefantrine may affect the liver, especially the double therapeutic dose levels. However, a strong conclusion cannot be made on this as ALT, which is a more specific hepatic enzyme (McClatchey, 2002) was not affected by both ACTs. Further, since the observed effects were reversed when drug treatments were stopped, it is logical to consider that the ACTs are incapable of posing serious toxicity to the liver.

Elevation of urea and creatinine levels is an indication of renal dysfunction (Mouton and Holder, 2006; Traynor et al., 2006). In the present study, artemether-lumefantrine did not alter plasma urea nor creatinine concentration, whereas artesunate-SP did not affect urea, but increased creatinine level at its double therapeutic dose. Interestingly, it was also observed that the urea and creatinine elevations by the two ACTs were reversed after termination of drug treatments, suggesting that all the ACTs evaluated lack renal toxicity potential in the guinea pig. In addition, artesunate-amodiaquine increased plasma urea and creatinine concentrations at normal and double therapeutic doses; urea was reversible while creatinine remained elevated (in double therapeutic dose treated animals) after drug discontinuation. This indicates that prolong treatment with double therapeutic dose of artesunate-amodiaquine may affect kidney function in the guinea pig.

Dyslipidemia is recognized as a prominent risk factor of cardiovascular disease (Yusuf et al., 2004) and elevation of blood cholesterol level has particularly been linked to elevation in blood pressure and coronary heart disease (Cotran, 1999). Previously, Edikpo et al. (2014) have demonstrated that treatment of mild and moderate cases of malaria with artemether reduced serum HDLcholesterol concentration. Additionally, therapeutic doses of artemether-lumefantrine and artesunateamodiaquine combinations have been shown to cause non-significant reduction of cholesterol level in plasma (Otuechere et al., 2012). These results do not however address prolong or higher therapeutic dose treatments, as only therapeutic doses of the drugs were used. In this study, lipids were unaffected by the artesunateamodiaquine, artesunate-SP and artemether- 
lumefantrine, except triglyceride which was elevated by double therapeutic dose of artesunate-SP treatment. This indicates that artesunate-amodiaquine and artemetherlumefantrine would not have adverse effects on cardiovascular function over the dose range used in this study. These observations were not different from the results obtained with the therapeutic dose treatments earlier reported. Furthermore, although, overdose treatment with artesunate-SP raised serum triglyceride concentration, since this elevation was reversible, prolong treatment may not induce persistent lipid alteration of pathological concern. However, longer duration of drug treatment as well as preexisting metabolic and/or cardiovascular diseases or risk factors may promote artesunate-SP toxicity.

\section{Conclusion}

Subacute treatment with normal therapeutic doses of artesunate-amodiaquine, artesunate-SP and artemetherlumefantrine do not alter plasma levels of hepatic enzymes, renal indices (urea and creatinine) and lipids, but double therapeutic levels reversibly increase hepatic and renal indices in the guinea pig.

\section{Acknowledgement}

The authors thank the laboratory staff of the Department of Pharmacology, University of Port Harcourt, Nigeria for providing technical assistance.

\section{Authors' Contributions}

All authors conceived and designed the study. Mankwe and Aprioku managed the literature searches. Mankwe conducted the experiments, collected and analyzed the data. Aprioku wrote the first draft of the manuscript. All authors revised the manuscript and approved the final manuscript.

\section{Funding Information}

The authors have no support or funding to report.

\section{Conflict of Interests}

The authors declare that there is no conflict of interest.

\section{References}

Adaramoye, O.A., D.O. Osaimoje, A.M. Akinsanya, C.M. Nneji and M.A. Fafunso et al., 2008. Changes in antioxidant status and biochemical indices after acute administration of artemether, artemetherlumefantrine and halofantrine in rats. Basic Clin. Pharmacol. Toxicol., 102: 412-418.

DOI: $10.1111 / \mathrm{j} .1742-7843.2008 .00211 . \mathrm{x}$
Adjuik, M., P. Agnamey, A. Babiker, S. Borrmann and P. Brasseur et al., 2002. Amodiaquine-artesunate versus amodiaquine for uncomplicated plasmodium falciparum malaria in African children: A randomised, multicentre trial. Lancet, 359: 1365-1372. DOI: $10.1016 / \mathrm{S} 0140-6736(02) 08348-4$

Akanbi, O.M., A.B. Odaibo, K.A. Afolabi and O.G. Ademowo, 2005. Effect of self-medication with antimalarial drugs on malaria infection in pregnant women in South Western Nigeria. Med. Princ. Pract., 14: 6-9. DOI: 10.1159/000081915

Aprioku, J.S. and A.W. Obianime, 2011. StructureActivity-Relationship (SAR) of artemisinins on some biological systems in male guinea pigs. Insight Pharmaceutical Sci., 1: 1-10. DOI: 10.5567/IPHARMA-IK.2011.1.10

Basco, L.K., A. Same-Ekobo, V.F. Ngane, M. Ndounga and T. Metoh et al., 2002. Therapeutic efficacy of sulfadoxine-pyrimethamine, amodiaquine and the sulfadoxine-pyrimethamine-amodiaquine

combination against uncomplicated Plasmodium falciparum malaria in young children in Cameroon. Bulletin World Health Organization, 80: 538-545. DOI: $10.1590 / \mathrm{S} 0042-96862002000700005$

Barnes, K.I., D.N. Durrheim, F. Little, A. Jackson and U. Mehta et al., 2005. Effect of artemetherlumefantrine policy and improved vector control on malaria burden in KwaZulu-Natal, South Africa. PLoS Medicine, 2: e330. DOI: 10.1371/journal.pmed.0020330

Bhattacharyya, D., R. Mukherjee, S. Pandit, N. Das and T.K. Sur, 2003. Prevention of carbon tetrachloride induced hepatotoxicity in rats by Hmmoliv (a poly herbal formulation). Ind. J. Pharmacol., 35: 183-185.

Breman, J.G., M.S. Alilio and A. Mills, 2004. Conquering the intolerable burden of malaria: What's new, what's needed: A summary. Am. J. Trop. Med. Hygiene, 71: 1-15.

Djimdé, A., O.K. Doumbo, J.F. Cortese, K. Kayentao and S. Doumbo et al., 2001. A molecular marker for chloroquine-resistant falciparum malaria. New Engl. J. Med., 344: 257-263. DOI: $10.1056 /$ NEJM200101253440403

Edikpo, N., P.O. Okonkwo and E. Adikwu, 2014. Effect of artemether treatment on plasma lipid profilein malaria. Pharmacol. Pharmacy, 5: 646-656. DOI: $10.4236 /$ pp.2014.57074

Etim, O.E., U.E. Bassey, G.E. Charles, E.E. Sambo and E.J. Akpan et al., 2016. Toxicological evaluation of some Artemisinin Combination Therapies (ACTs) on the kidney and liver of albino Wistar rats. Int. J. Biochem. Res. Rev., 9: 1-5. DOI: $10.9734 /$ IJBCRR/2016/22846

Harinasuta, T. and J. Karbwang, 1994. Qinghaosu: A promising antimalarial. J. Am. Med. Association, SEA, 34: 7-8. 
Hien, T.T., 1994. An overview of the clinical use of artemisinin and its derivatives in the treatment of falciparum malaria in Viet Nam. Trans. Royal Society Trop. Med. Hygiene, 88: 7-8.

DOI: 10.1016/0035-9203(94)90461-8

Heppner, D.G. and W.R. Ballou, 1998. Malaria in 1998: Advances in diagnosis, drugs and vaccine development. Current Opin. Infect. Dis., 11: 519-530.

Jaeger, A., P. Sauder, J. Kopferschmitt and F. Flesch, 1987. Clinical features and management of poisoning due to antimalarial drugs. Med. Toxicol. Adverse Drug Exp., 2: 242-273. PMID: 3306266

McClatchey, K.D., 2002. Clinical Laboratory Medicine. 1st Edn., Lippincott Williams and Wilkins, Philadelphia.

Mouton, R. and K. Holder, 2006. Laboratory tests of renal function. Anaesthesia Intensive Care Med., 7: 240-243. DOI: 10.1053/j.mpaic.2006.04.003

Nosten, F. and N.J. White, 2007. Artemisinin- based combination treatment of falciparum malaria. Am. J. Trop. Med. Hygiene, 77: 181-192. PMID: 18165491

Nwanjo, H.U., I.I. Iroagba, I.N. Nnatuanya and N.A. Eze, 2007. Antifertility activity of dihydroartemisinin in male albino rats. Int. J. Endocrinol., 4: 1-5. DOI: 10.1016/j.arabjc.2014.10.018

Nyblom, H., E. Björnsson, M. Simrén, F. Aldenborg and S. Almer et al., 2006. The AST/ALT ratio as an indicator of cirrhosis in patients with PBC. Liver Int., 26: 840-845. DOI: $10.1111 /$ j.1478-3231.2006.01304.x

Otuechere, C.A., Edewor, G., Kale, O.E. and M. Ekor, 2012. Subacute therapeutic dosing of artemetherlumefantrine and artesunate-amodiaquine combination preserves plasma cholesterol, renal antioxidant status and organ weights in rats. Malaria Res. Treatment, 2012: 5. DOI:10.1155/2012/257986

Raji, Y., T.O. Osonuga, O.S. Akinsomisoye, O.A. Osonuga and O.O Mewoyeka, 2005. Gonadotoxicity evaluation of oral artemisinin derivatives in male rats. J. Med. Sci., 5: 303-306.

DOI: $0.1016 / \mathrm{S} 2221-1691(12) 60083-5$
Rønn, A.M., H.A. Msangeni, J. Mhina, W.H. Wernsdorfer and I.C. Bygbjerg, 1996. High level of resistance of Plasmodium falciparum to sulfadoxinepyrimethamine in children in Tanzania. Transa. Royal Society Trop. Med. Hygiene, 90: 179-181. DOI: 10.1016/S0035-9203(96)90129-7

Sachs, J. and P. Malaney, 2002. The economic and social burden of malaria. Nature, 415: 680-685. DOI: $10.1038 / 415680 \mathrm{a}$

Traynor, J., C.C Geddes and J.G. Fox, 2006. How to measure renal function in clinical practice. British Med. J., 333: 333: 733. DOI: $10.1136 /$ bmj.38975.390370.7C

Ugian, E.A, K. Dasofunjo, J.N. Nwangwa, A.A. Asuk and M.S. Akam et al., 2013. Effect of artemisininbased combination therapy on some selected liver function indices of pregnant wistar albino rats. J. Applied Pharmaceutical Sci., 3: 152-154.

Yusuf, S., S. Hawken, S. Ounpuu, T. Dans and A. Avezum et al., 2004. Effect of potentially modifiable risk factors associated with MI in 52 countries (the INTERHEART study): Case-control study. Lancet, 364: 937-952. DOI: 10.1016/S0140-6736(04)17018-9

Cotran, K.C., 1999. Cellular Pathology. In: Robbins Pathologic Basis of Disease. Elsevier, UK.

Obianime, A.W. and J.S. Aprioku, 2011. Mechanism of action of artemisinins on biochemical, hematological and reproductive parameters in male guinea pigs. Int. J. Pharmacol., 7: 84-95. DOI: 10.3923/ijp.2011.84.95

Ogutu, B.R., B.L. Smoak, R.W. Nduati, D.A. MboriNgacha and F. Mwathe et al., 2000. The efficacy of pyrimethamine-sulfadoxine (Fansidar ${ }^{\circledR}$ ) in the treatment of uncomplicated Plasmodium falciparum malaria in Kenyan children. Trans. Royal Society Trop. Med. Hygiene, 94: 83-84. DOI: $10.1016 / \mathrm{S} 0035-9203(00) 90450-4$ 